\title{
Numerical Study of Stress Analysis for the Different Widths of Padding Welds
}

\author{
Adam Kulawik - Joanna Wróbel* \\ Faculty of Mechanical Engineering and Computer Science, Czestochowa University of Technology, Poland
}

In the presented study, the cases of regeneration of the element made of C45 steel, using the MAG (Metal Active Gas) method are analysed. The base material is applied to the regeneration process. The analysis of the influence of the padding weld width $(0.006 \mathrm{~m}, 0.01 \mathrm{~m}, 0.014$ $\mathrm{m})$ and the preheating temperature on the phase transformations and effective stresses of the regenerated layer are performed. A nonstandard approach to preheating (before each padding weld after the cooling to ambient temperature) is considered. Due to the possibility of simplifying the model from 3D to $2 \mathrm{D}$ (symmetry of calculations for long padding welds), calculations were performed using the finite element method in the transverse to the padding direction. Each new padding weld was included as an additional area in the finite element mesh. The developed numerical model includes a temperature model, phase transformations in the liquid and solid states, and the stress model in the elastic-plastic range. The aim of the regeneration is not only to obtain the original geometry of the element, but it is also important that the filler material used (in the considered case identical to the base material) has appropriate properties. These properties largely depend on the phase composition. The used filler material affects not only the hardness, brittleness, and ductility of the material. Its kinetics and changes in the geometry can cause significant stresses and even cracks. Based on the obtained results, it can be concluded that increasing the width of the padding welds causes a decrease in the level of residual effective stress; however, it is technologically difficult to accomplish. The most unfavourable stresses occur in the initial area of the pad welding zone. For lower preheating temperatures and smaller welds, areas with possible cracks are identified. In these cases, lower preheating and tempering should be carried out, which leads to similar energy costs as at higher preheating temperatures. Due to the complex phase transformation process for medium carbon steels and the need for the process parameters control, proper regeneration is possible only in automated workstations.

Keywords: computational mechanics, numerical simulation, padding weld, preheating, strain analysis, stress

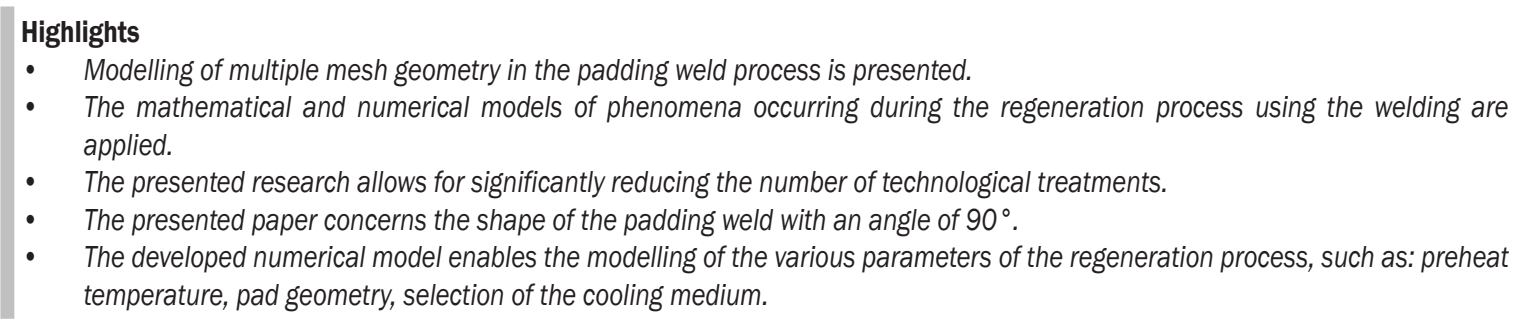

\section{O INTRODUCTION}

The medium $\mathrm{C} 45$ carbon steel is suitable for annealing, weldable, and an easy-to-heat treatment. It is a durable steel with significant ductility [1]. C45 steel is used for the moderately loaded and abrasionresistant machine and equipment parts, such as spindles, axles, shafts, gear wheels, shafts of electric motors, discs, screws, wheel hubs, as well as for moulds in plastics processing. Because the range of regenerated $\mathrm{C} 45$ steel parts is extensive, in this paper only the application of new layers to the thin-walled element is analysed. Due to the need to obtain hard coatings, especially during exposure to abrasion, it is necessary to control phase changes during cooling and reheating. Components made of the tested material make it possible to obtain high surface hardness (50 HRC).
The modelling of the multi-pass pad welding process is not a common topic of research papers. Due to the experimental approach for solving these problems, expensive test stands are most often used. For example, thermal analyses obtained from thermovision cameras for process control are used [2]. The data obtained from these analyses can be successfully used to calibrate much cheaper numerical models. Modelling in the field of thermal phenomena in the pad-welding process of a multilayer or multi-pass is performed even for the complex geometries. However, such models most often refer to the thermal phenomena and compare temperatures obtained from numerical analysis to results obtained from experiments, such as the heat-affected zone (HAZ), hardness, and phase compositions [3]. In the welding or pad welding technology, a highly accurate process temperature is required (at different points of geometry). This approach allows one to, for example, 
control the grain size as well as the temperature of the start and finish of martensite transformation [4].

Existing works show that the multi-layer thermal cycle for some materials can have a weakening effect on mechanical properties [5]. However, there are contraindications to the use of large crosssectional welds or padding welds due to unfavourable segregation of dopant and excessive strains.

In pad-welding technology, there are also interesting studies on cladding the parent material with several layers of different materials. However, due to the low thickness of the obtained coating and the depth of HAZ, the stress analysis of these examples cannot be referred to as typical padding welds [6]. Thin layers of padding welds, in cases in which the area of the base material is much larger, are characterized by a small thermal influence on this area. With a significant level of heat dissipation from the padding welds, a martensitic transformation may take place in the case of thin padding layers. Due to the large volume changes during the martensitic transformation, the padding of thin layers is made of materials without phase transformations in a solid state. The residual stress analysis is more often performed by the authors of papers on repair welds, in which the system of the next padding welds has a vertical direction [7] and [8]. In these cases, it is necessary to use the next small cross-sectional layers of padding weld. The use of a large padding weld would be unfavourable, for example, due to higher thermal loads or segregation of the admixture. This fact applies especially to corrosion-resistant materials; however, the influence of phase changes is most often not analysed, which is justified by the fact that such materials have a small change in microstructure, which cannot be said about medium carbon steel analysed in the paper.

Regenerative pad welding is a complex process, and the regeneration of even a geometrically simple surface may involve the necessity of different position and direction of padding welds [9]. In cases of modelling the pad welding processes for large areas with layers of welds with different orientations, threedimensional (3D) modelling should be performed. It is not possible to perform the analysis only in the cross-section.

The presented research allows one to reduce the number of technological treatments significantly. Due to the need to obtain a specific hardness of the hardfacing for various applications of C45 steel (steel with high carbon equivalent), it is necessary to choose the appropriate preheating temperature range. The ease of formation of the hardening structures of $\mathrm{C} 45$ steel during the hardfacing/welding often leads to high stresses and, consequently, cracks. The basic method of preventing cold cracks is preheating, which allows for more flexible transition structures, e.g., bainite [10]. The presented paper concerns the shape of the padding weld with an angle of $90^{\circ}$. In accordance with the requirements of the norm EN ISO 5817 [11] quality $\mathrm{D}$, this weld toe is the worst of the technologically possible solutions. It is also necessary to choose the padding weld width for economic reasons and the obtained stress states (the possibility of surface cracks and on the entire height of the padding weld). In both experimental and numerical studies, the authors most often analyse the shape of the padding welds with a quality level higher than D [12] and [13].

This paper is an extension of the analyses carried out in the research contained in the earlier work [14]. The authors analysed different preheating temperatures for one width of the padding weld. However, they did not discuss the choice of the width of the padding weld for the regeneration process of medium-carbon steel. In this paper, distinct from previous research [14], the application of both smaller and larger padding weld widths $(0.006 \mathrm{~m}, 0.01 \mathrm{~m}, 0.014 \mathrm{~m})$ was analysed. In order to obtain the correct regenerative padding weld (PW) without any nonconformities 12 cases of combinations of different preheating temperatures and widths of the padding weld are analysed in this paper. The use of numerical simulations reduces the cost of experiments. Using them on a wider scale allows for multi-criteria analysis, based on which we can obtain optimal parameter values. All calculations were performed on a copyrighted application. This model contains appropriate relationships between elements regarding temperature modelling and phase transformation occurring in the range above and below liquidus temperature $\left(T_{L}\right)$ and solidus temperature $\left(T_{S}\right)$. The relationships between the above models and the model of mechanical phenomena are also taken into account.

\section{COMPUTATIONAL MODEL}

In this paper, the computational model of phenomena taking place during the regeneration of parts is the same as for welding modelling. The model is composed of a module of heat treatment modelling (Fig. 1) and a module taking into account mechanical phenomena (Fig. 3). The phase transformations of austenite to ferrite, pearlite, bainite, martensite and reverse transformations were considered (Fig. 2). The solidification process was analysed in the model. Couplings between the elements of the model were also included. 


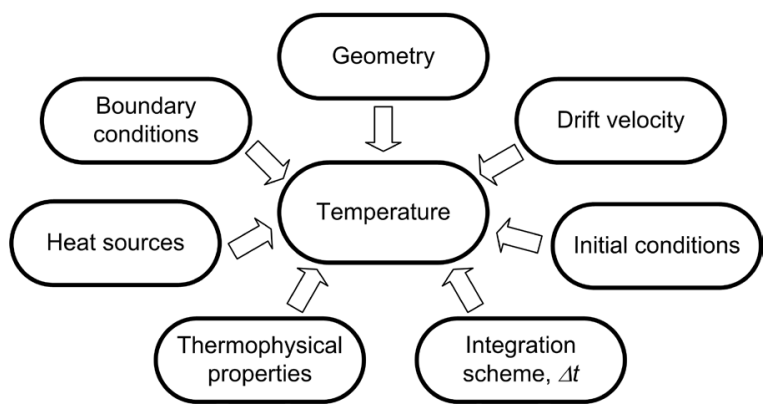

Fig. 1. Elements of the thermal phenomena model for the regeneration process

The process of regeneration of steel elements depends mainly on the temperature factor. Therefore, not including the main elements in the heat transfer model can lead to significant simulation errors (Fig. 1). Large temperature changes over time required the solution of the non-steady-state heat transfer equation in the following form:

$$
\nabla \cdot(\lambda \nabla T)-\rho C \frac{\partial T}{\partial t}=0,
$$

where $T[\mathrm{~K}]$ is the temperature, $t[\mathrm{~s}]$ the time, $\lambda[\mathrm{W} /(\mathrm{mK})]$ is the thermal conductivity, $\rho\left[\mathrm{kg} / \mathrm{m}^{3}\right]$ is the mass density, and $C[\mathrm{~J} /(\mathrm{kgK})]$ is the effective thermal capacity.

The material properties assumed in the computation were dependent on temperature and the phase fractions [15]. The use of constant material properties from temperature causes very large computation errors.

The model of solidification process takes into account the heat of transformation as a change of the effective heat capacity $C_{e f}$ of the material [16] and [17]:

$$
C_{e f}=\rho(T)-C(T)-\left.\rho_{S} L \frac{\partial f_{s}(T)}{\partial T}\right|_{T_{S}} ^{T_{L}},
$$

where $L[\mathrm{~J} /(\mathrm{kgK})]$ is the latent heat of transformation, $f_{s}$ share of the solid phase, $T_{L}$ liquidus temperature, and $T_{S}$ solidus temperature.

In Eq. (2), the $f_{S}$ is resolved by the lever rule:

$$
f_{S}=f_{S}(T)=\frac{T_{L}-T}{T_{L}-T_{S}}, \quad T \in\left[T_{L}, T_{S}\right]
$$

Changes in the phase composition during the cooling and heating are calculated on the basis of the analysis of continuous cooling transformation (CCT) and continuous heating transformation (CHT) diagrams [18]. The data obtained from the diagrams are input to the macroscopic model, in which the modified Koistinen-Marburger equation was used for the high-rate cooling process [19] and [20]:

$$
\tilde{\eta}_{\gamma}(T, t)=1-\exp \left(-\frac{4.60517}{T_{s \gamma}-T_{f \gamma}}\left(T_{s \gamma}-T\right)\right),
$$

where $\tilde{\eta}_{\gamma}$ is the austenite fraction, $T_{s \gamma}$ is the austenite start temperature, $T_{f y}$ is the austenite finish temperature.

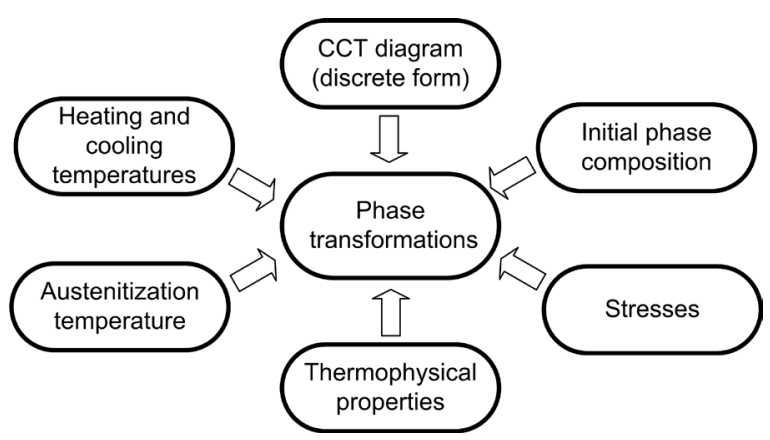

Fig. 2. Elements of the phase transformations model for the regeneration process

The phase transformations described by Eq. (4) take place only in the area where the padding welds reheat the element. It is assumed that austenite is the first structure formed after solidification during the cooling process. In the model of phase transformations during the heating, the ferrite and pearlite are treated as a homogeneous mixture.

The phase transformations of the cooling process $\eta_{(i)}(T, t)$ (except for the martensite phase) are determined on the basis of a macroscopic model based on the Avrami equation [21]:

$$
\begin{aligned}
& \eta_{(i)}(T, t)= \\
& \min \left\{\eta_{(i \%)}, \tilde{\eta}_{\gamma}-\sum_{j \neq i} \eta_{j}\right\} \cdot \exp \left(-\frac{0.01005}{t_{s}^{n(T)}} t^{n(T)}\right), \\
& n(T)=\frac{\ln \left(\frac{\ln \left(1-\eta_{f}\right)}{\ln \left(1-\eta_{s}\right)}\right)}{\ln \left(\frac{t_{f}(T)}{t_{s}(T)}\right)}
\end{aligned}
$$

where $\eta_{(i \%)}$ is the final fraction of $i$ phase, $\eta_{j}$ is the phase during cooling, $n(T)$ functions depending on the start and finish times of transformation $\left(t_{s}\right.$ and $\left.t_{f}\right)$.

During the cooling process, the transformations of austenite $\rightarrow$ ferrite, austenite $\rightarrow$ pearlite are considered separately. 
The kinetics of martensite transformation $\eta_{M}(T, t)$ for medium-carbon steel is determined on the basis of the Koistinen-Marburger equation [20]:

$$
\begin{aligned}
& \eta_{M}(T, t)= \\
& \left(\tilde{\eta}_{\gamma}-\sum_{j \neq M} \eta_{i}\right) \cdot\left(1-\exp \left(-0.01005\left(M_{S}-T\right)\right)\right),
\end{aligned}
$$

where $M_{S}$ is the start temperature of martensite transformation.

When the next padding welds appear, the martensite formed during the cooling process is heated and transformed into tempered martensite $\eta_{T M}(T, t)$. This process is described by the formula:

$$
\eta_{T M}(T, t)=\eta_{M}\left(1-\exp \left(-\frac{0.01005}{t_{s}^{n(T)}} t^{n(T)}\right)\right)
$$

The parameters in Eq. (7) describe the transformations of martensite $\rightarrow$ tempered martensite and are determined based on the equations in the experiment [22].

The phase transformations in the solid-state and temperature changes influence the stress state through the thermal $\varepsilon^{T}$ and structural $\varepsilon^{P h}$ strains described by the following equation:

$$
\begin{gathered}
\Delta \varepsilon^{T P h}=\Delta \varepsilon^{T}+\Delta \varepsilon^{P h}, \\
\Delta \varepsilon^{T}=\Sigma_{i} \alpha_{i}(T) \eta_{i} \Delta T, \\
\left.\Delta \varepsilon^{P h}=\operatorname{sign}(-\Delta T) \Sigma_{i} \varepsilon_{i}^{P h}(T) \Delta \eta\right),
\end{gathered}
$$

where $\alpha_{i}(T)$ is the coefficients of thermal expansion, $\varepsilon_{i}^{P h}(T)$ is the coefficient of strain expansion.

The material properties were taken from the experiment performed for C45 steel [19]. The thermal expansion coefficients and start and end times of tempered martensite were reported in paper [22].

The equilibrium equation, in incremental form, taking into account the influence of temperature on material properties, was used to calculate the stress state. The model did not assume any external forces or the influence of gravity.

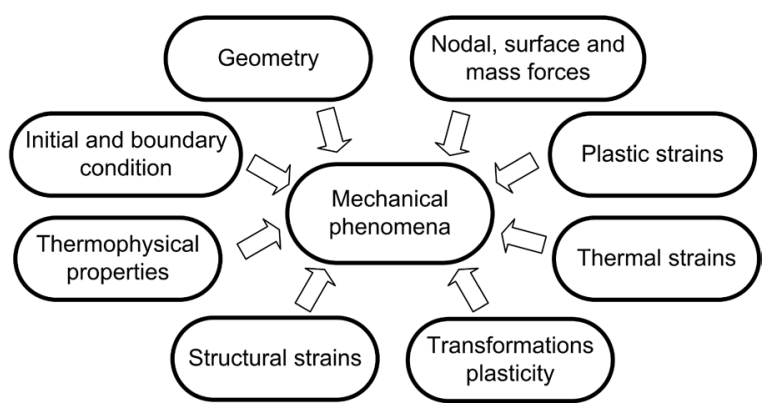

Fig. 3. Elements of the mechanical phenomena model for the regeneration process
The elastic deformations are, therefore, the difference between the total, thermal, structural, plastic strains and the transformations plasticity. The influence of temperature on Young's modulus is taken into account.

In the described elastic-plastic model, the isotropic hardening was assumed. The GreenwoodJohnson mechanism in the formation of the transformations' plasticity was also taken into account [23] and [24]. According to the results of the experiments, the temporary yield point is dependent on the temperature and the phase composition (Fig. 4) [25].

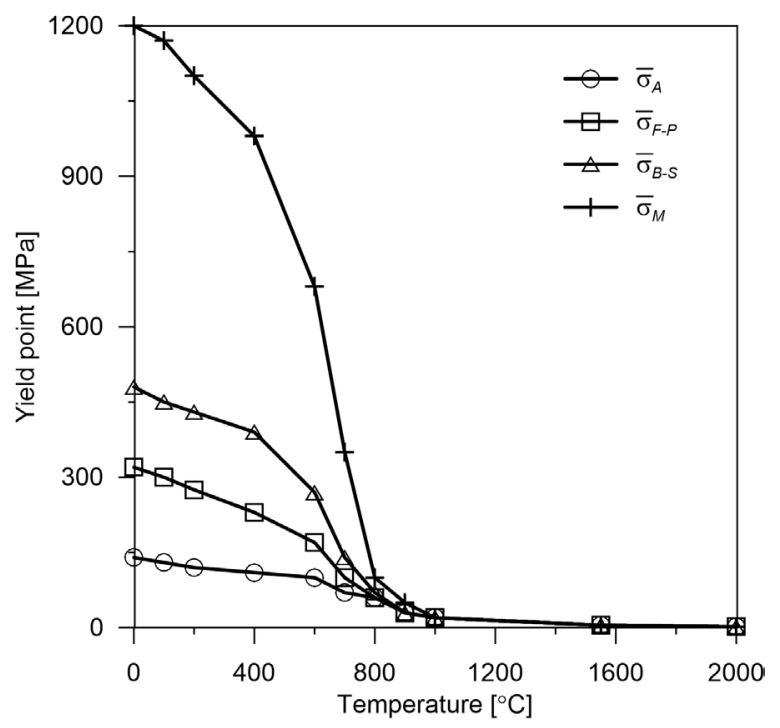

Fig. 4. Yield point and Young's modulus for particular phases for C45 steel

All results presented were obtained from the application developed by the authors of this paper. Calculations were made in Visual Studio $\mathrm{C}++$. Linear algebra functions were taken from the Intel ${ }^{\circledR}$ Math Kernel Library [26]. The developed numerical model allows for the modelling of various parameters of the regeneration process, such as preheat temperature, pad geometry, selection of the cooling medium and consideration of heat dissipation by the regeneration station.

\section{SIMULATION EXAMPLE}

In numerical simulations, it was assumed that the tested plate made of medium carbon steel was a regenerated multipath by applying the next padding welds. In this paper, it was simplified so that the process can be approximated by a $2 \mathrm{D}$ model by analysing the cross-section of the element (across the 


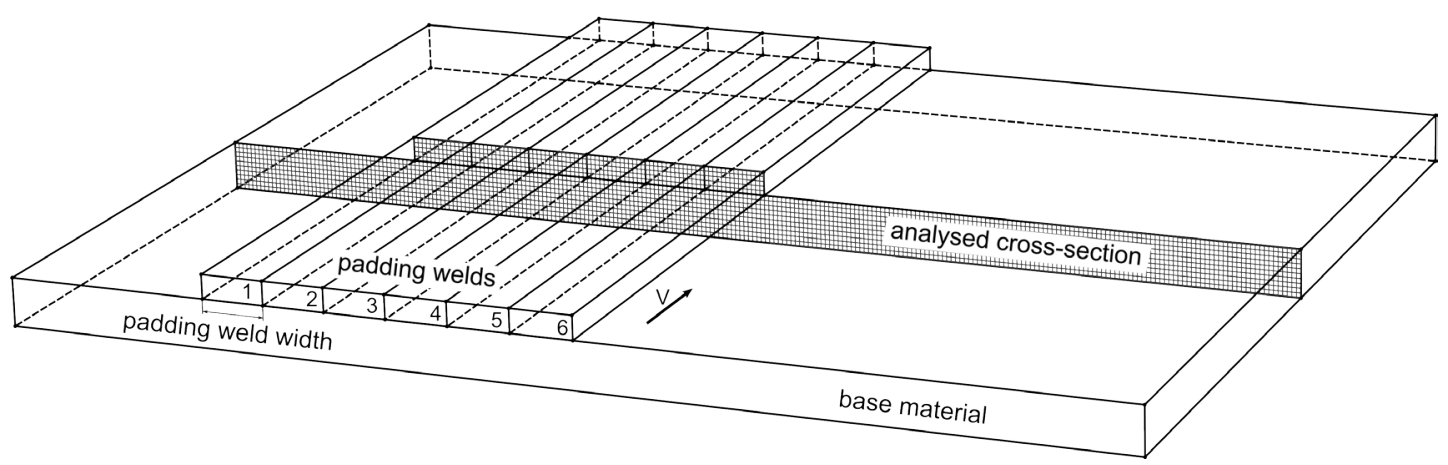

Fig. 5. Overview figure for analysis No. 3

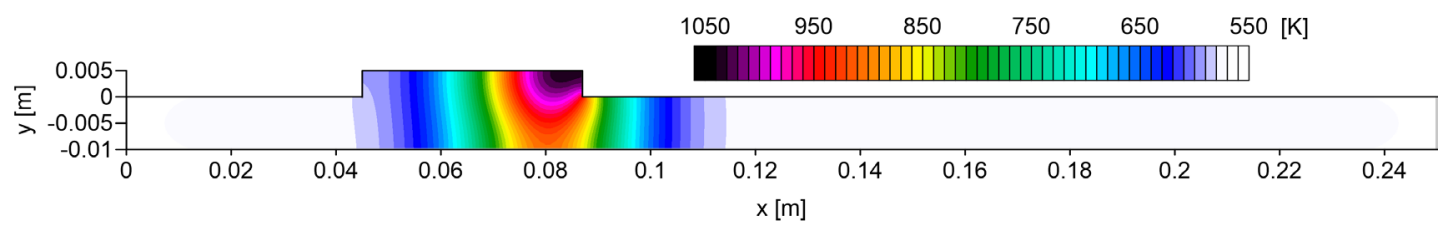

Fig. 6. The temperature field $[\mathrm{K}]$ for the third padding weld of width $0.014 \mathrm{~m}\left(T_{0}=573 \mathrm{~K}\right)$ after time $t=9 \mathrm{~s}$

PW) (Fig. 5). Because the geometry of the padding weld is characterized by a significant predominance of length over width and usually a quite high pad welding speed, critical data concerning stresses, for example, can be obtained mainly from the crosssection. Pad welding with a single path (at one time) and starting subsequent paths after reaching a relatively low temperature of the previous padding weld additionally ensures the correctness of the analysed cross-section. The width of the analysed plate was $0.25 \mathrm{~m}$, the thickness $0.01 \mathrm{~m}$, while the padding weld height was $0.005 \mathrm{~m}$ (Fig. 6). Three cases were considered for a different padding weld width: $0.006 \mathrm{~m}, 0.01 \mathrm{~m}$ and $0.014 \mathrm{~m}$ (Table 1). To ensure a similar amount of welded material, it was adopted that the PW was composed by the 14 beads for the first case, 8 beads for the second, and 6 beads for the third. In all the analysed cases, the first padding weld is located $0.045 \mathrm{~m}$ to the edge. The geometry of the PW is approximated by a quads element (Fig. 5). Finite element mesh with quads elements and bilinear approximation was used for calculations [27]. The padding weld element was discredited by 250 elements in length and 10 in height (element size $0.001 \times 0.001)$. Each padding weld was approximated with finite elements of the same size: analysis No. 1: 6×5, analysis No. 2: $10 \times 5$ and analysis No. 3: $14 \times 5$ (Fig. 5). According to the welding standard ISO 5817 [11] the weld toe equally $90^{\circ}$ was adopted (limit for imperfections for quality level D). The technological process was simplified; it was assumed that the padding weld appears as a rectangular element with a given height and width (constant height, 3 cases of width) and an initial temperature of $3000 \mathrm{~K}$ (Fig. 7). The constant initial temperature of the PW and its different cross-sectional area were assumed; from the technological side, it requires the delivery of different amounts of heat (different parameters of the welding arc).

For all analysed padding weld widths, the four preheating temperatures: $T_{0}=293 \mathrm{~K}, 373 \mathrm{~K}, 473 \mathrm{~K}$, $573 \mathrm{~K}$ were considered. The cooling on the boundaries was modelled with the Newton condition (Fig. 6). Air cooling was modelled according to the equation [28]:

$$
\alpha_{\text {air }}=\left\{\begin{array}{l}
0.0668 \times T, \quad T_{0}<T<773 \mathrm{~K} \\
0.231 \times T-82.1, \quad T \geq 773 \mathrm{~K}
\end{array} .\right.
$$

Table 1. Numerical research plan

\begin{tabular}{|c|c|c|c|c|}
\hline $\begin{array}{c}\text { Analysis } \\
\text { No. }\end{array}$ & $\begin{array}{c}\text { Preheating } \\
\text { temperature [K] }\end{array}$ & $\begin{array}{l}\text { PW width } \\
\text { [m] }\end{array}$ & $\begin{array}{l}\text { Number } \\
\text { of PW }\end{array}$ & $\begin{array}{c}\text { Field of the PW } \\
\text { area }\left[\mathrm{m}^{2}\right]\end{array}$ \\
\hline 1.1 & 293 & \multirow{4}{*}{0.006} & \multirow{4}{*}{14} & \multirow{4}{*}{0.00042} \\
\hline 1.2 & 373 & & & \\
\hline 1.3 & 473 & & & \\
\hline 1.4 & 573 & & & \\
\hline 2.1 & 293 & \multirow{4}{*}{0.01} & \multirow{4}{*}{8} & \multirow{4}{*}{0.0004} \\
\hline 2.2 & 373 & & & \\
\hline 2.3 & 473 & & & \\
\hline 2.4 & 573 & & & \\
\hline 3.1 & 293 & \multirow{4}{*}{0.014} & \multirow{4}{*}{6} & \multirow{4}{*}{0.00042} \\
\hline 3.2 & 373 & & & \\
\hline 3.3 & 473 & & & \\
\hline 3.4 & 573 & & & \\
\hline
\end{tabular}


For each case, calculations were performed for many finite element method (FEM) meshes. Each subsequent geometry differed in the formation of one padding weld. The number of simulations depended on the number of PW in each case (Table 1). The assumption of a small value of finite elements defining the padding weld allowed one to observe the changes in the analysed phenomena.
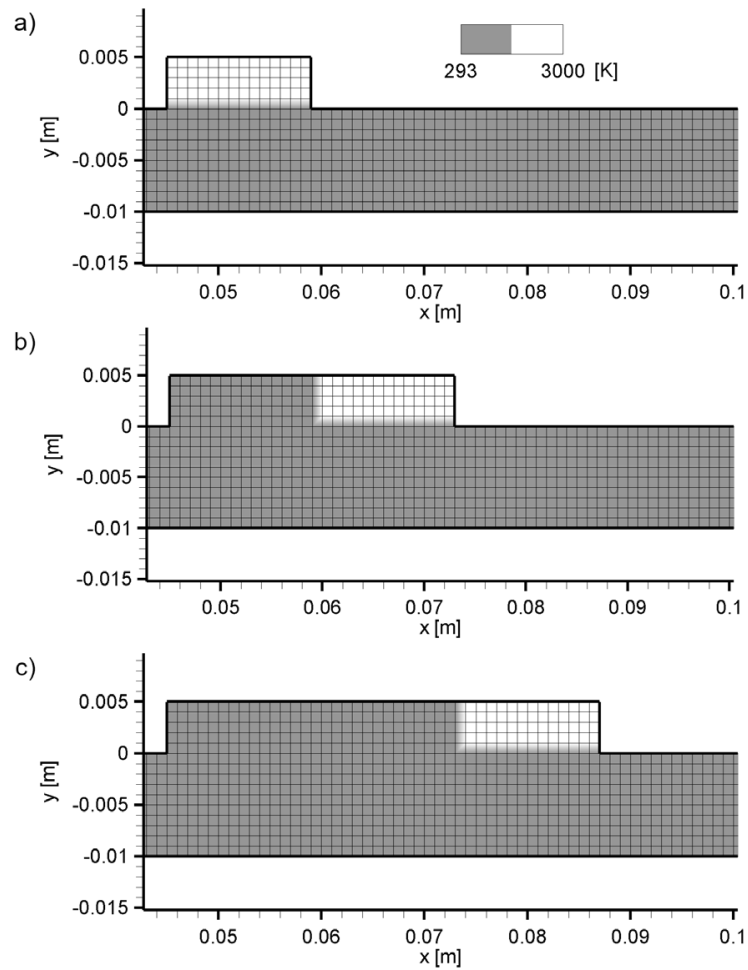

Fig. 7. Geometry with mesh and initial temperature for the next three padding welds (analysis No. 3): a) one padding weld, b) two padding welds, c) three padding welds

The appearance of the next PW was dependent on the value of temperature. Subsequent weld passes occurred after reaching the ambient temperature of the previous PW. The next step was to set the preheating temperature for the next padding weld and the whole element. The analysed material for the assumed cooling conditions (after the cooling process) does not contain an austenitic structure. In the model of mechanical phenomena, appropriate degrees of freedom were removed for selected elements; therefore, the model could be solved numerically. The selected nodes and applied zero displacements did not of the obtained stress levels. Due to large changes in material properties, the average values of material properties were determined for each finite element in the mechanical model. These properties depend (among other factors) on temperature level, phase transformations in the solid state, and solidification (Fig. 4).

Each case is a series of a few successive simulations. The model assumes the continuity of values for phase transitions and stress state between successive simulations.

\section{RESULTS AND DISCUSSION}

One of the main parameters, especially for the materials subject to phase transformations during the regeneration process, is the depth of the heat-affected zone (HAZ) and fusion zone (FZ). Figs. 8 to 10 show the HAZ depth in the base material below the padding weld. The results of calculations for the four preheating temperatures for each of the three widths were presented. The size of the HAZ was determined assuming a temperature of $A_{c 1}$ for the steel $\mathrm{C} 45$ equal to $1008 \mathrm{~K}$.

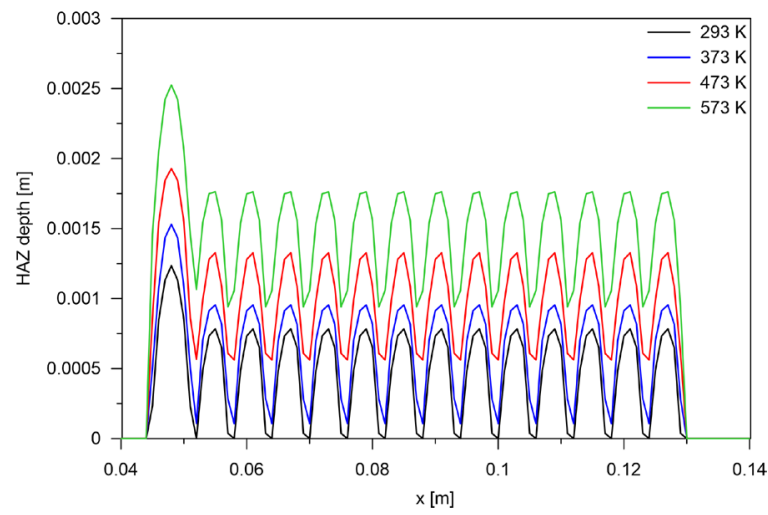

Fig. 8. Depth of HAZ for padding weld width of $0.006 \mathrm{~m}$

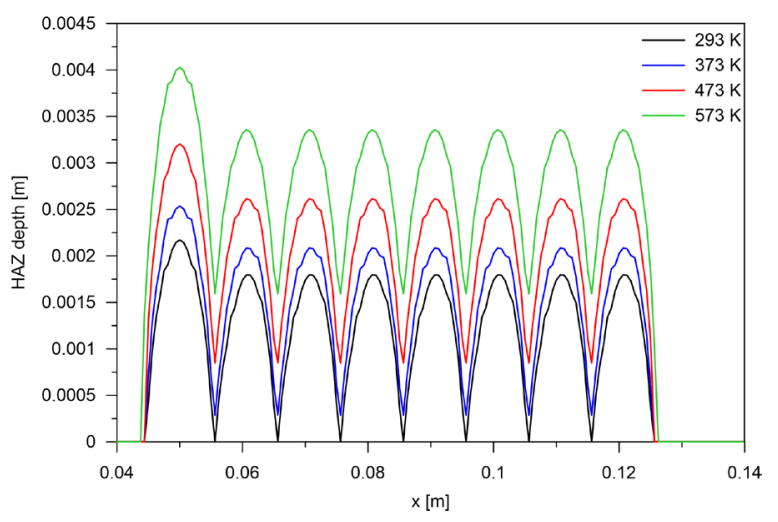

Fig. 9. Depth of HAZ for padding weld width of $0.01 \mathrm{~m}$

The change of HAZ depth depending on the preheating temperature in relation to the padding weld width was linearly correlated and increased with the size of the padding weld. In Figs. 8 to 10, it can be 
observed that the first padding weld causes the deepest HAZ, which is because three walls are cooled by air, and most of the heat is absorbed by the regenerated material. In other cases, contact with the regenerated material was through two walls of the padding weld. The largest difference between the depths of the HAZ was observed for the smallest width of the padding weld (Figs. 8 to 10). In this case, proportionally, the smallest length of the edge is in contact with the regenerated material. According to predictions, the greatest depth of HAZ occurs for the largest volume of the padding weld (Fig. 10). On the basis of the obtained temperature distribution in the area of contact between the padding welds and the base material, the depth of the fusion zone was minimal, and only the nodes of the finite element mesh on the border of the base area exceed the temperature $T_{L}=1750 \mathrm{~K}$.

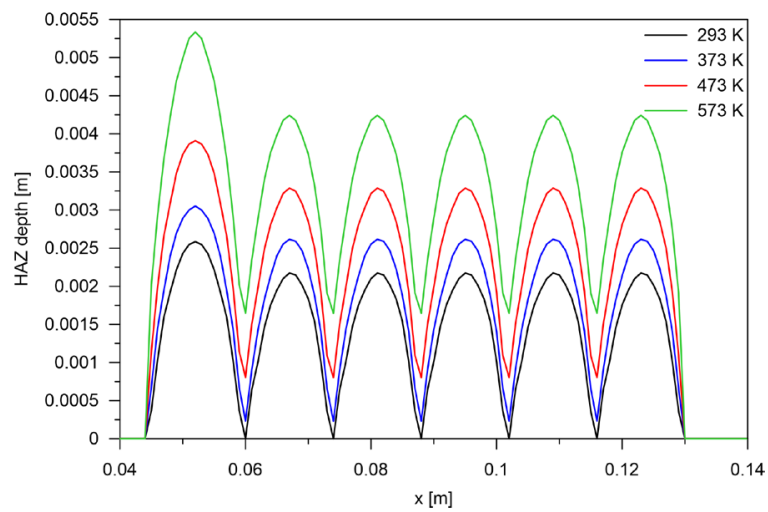

Fig. 10. Depth of HAZ for padding weld width of $0.014 \mathrm{~m}$

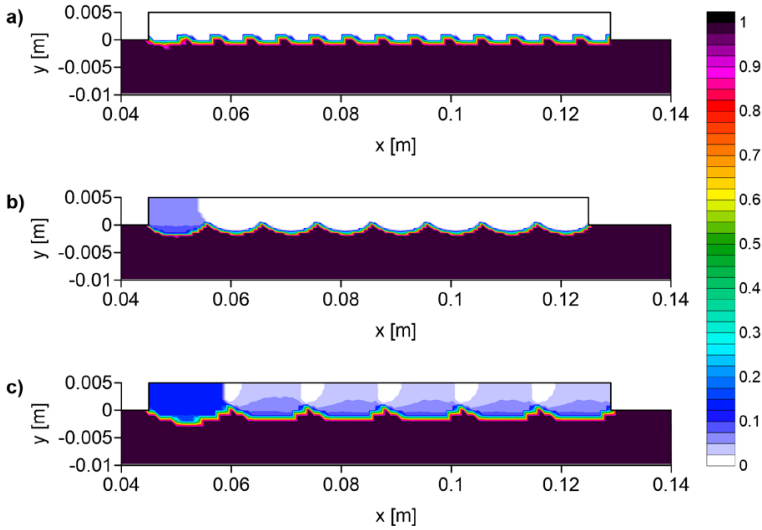

Fig. 11. Sum of ferrite and pearlite fraction (after process), preheating temperature $293 \mathrm{~K}$ and padding weld width of:

$$
\text { a) } 0.006 \mathrm{~m}, \mathrm{~b}) 0.01 \mathrm{~m}, \mathrm{c}) 0.014 \mathrm{~m}
$$

It can be observed that for the smallest padding weld for the first two preheating temperatures, the cooling rate exceeds critical velocity (rate of obtaining the quenching phase), which also applies to the first
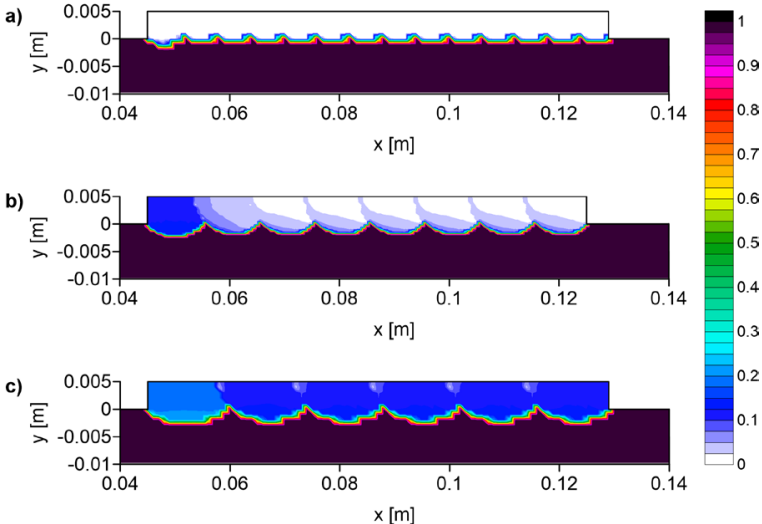

Fig. 12. Sum of ferrite and pearlite fraction (after process), preheating temperature $373 \mathrm{~K}$ and padding weld width of: a) $0.006 \mathrm{~m}, \mathrm{~b}) 0.01 \mathrm{~m}, \mathrm{c}) 0.014 \mathrm{~m}$
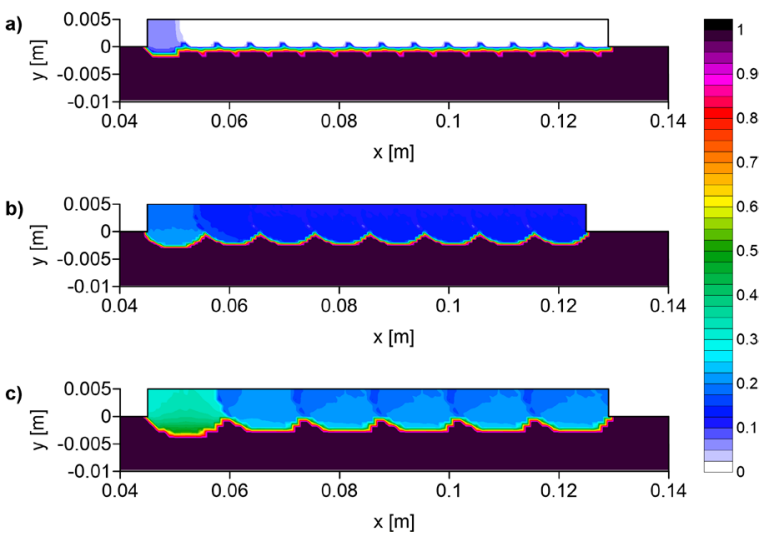

Fig. 13. Sum of ferrite and pearlite fraction (after process), preheating temperature $473 \mathrm{~K}$ and padding weld width of: a) $0.006 \mathrm{~m}, \mathrm{~b}) 0.01 \mathrm{~m}, \mathrm{c}) 0.014 \mathrm{~m}$
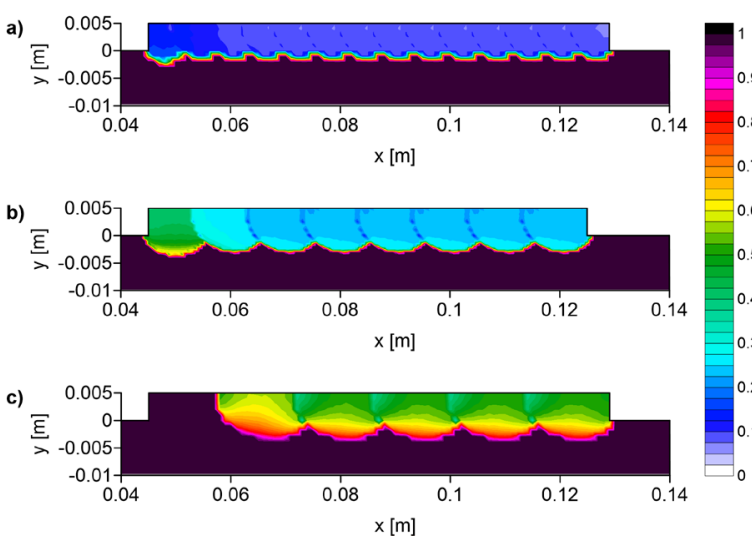

Fig. 14. Sum of ferrite and pearlite fraction (after process), preheating temperature $573 \mathrm{~K}$ and padding weld width of:

a) $0.006 \mathrm{~m}, \mathrm{~b}) 0.01 \mathrm{~m}, \mathrm{c}) 0.014 \mathrm{~m}$

padding weld, for which the cooling is the slowest (the longest air-cooled boundary) (Figs. 11a and 12a). With the increase of the PW width and the preheating 
temperature, the cooling rate decreases to such a value that in the last case 3.4 (see Table 1, Fig. 14c) the first padding weld is composed only of a ferrite-pearlite mixture, whereas the others only in about $50 \%$ (Figs. 11 to 14$)$.
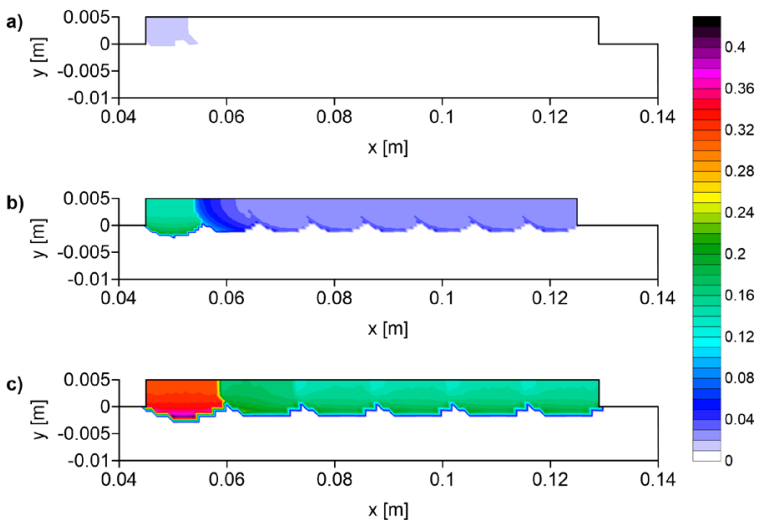

Fig. 15. Bainite fraction (after process), preheating temperature $293 \mathrm{~K}$ and padding weld width of:

a) $0.006 \mathrm{~m}, \mathrm{~b}) 0.01 \mathrm{~m}, \mathrm{c}) 0.014 \mathrm{~m}$
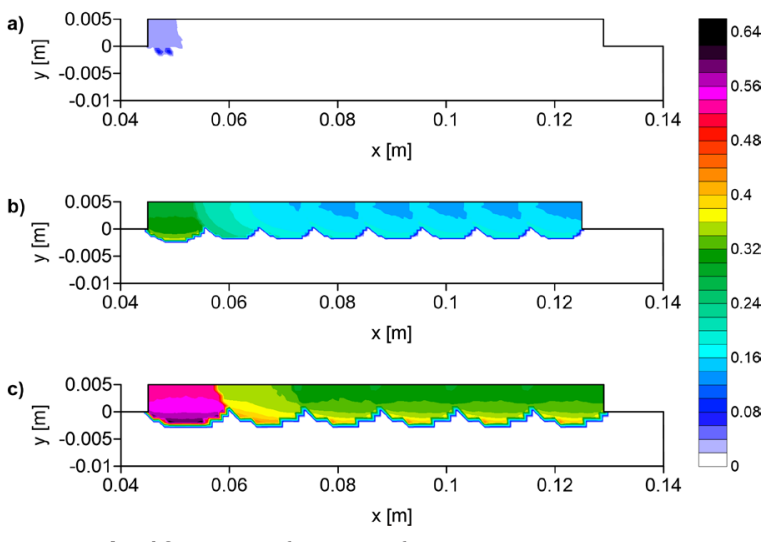

Fig. 16. Bainite fraction (after process), preheating temperature $373 \mathrm{~K}$ and padding weld width of: a) $0.006 \mathrm{~m}$, b) $0.01 \mathrm{~m}, \mathrm{c}) 0.014 \mathrm{~m}$
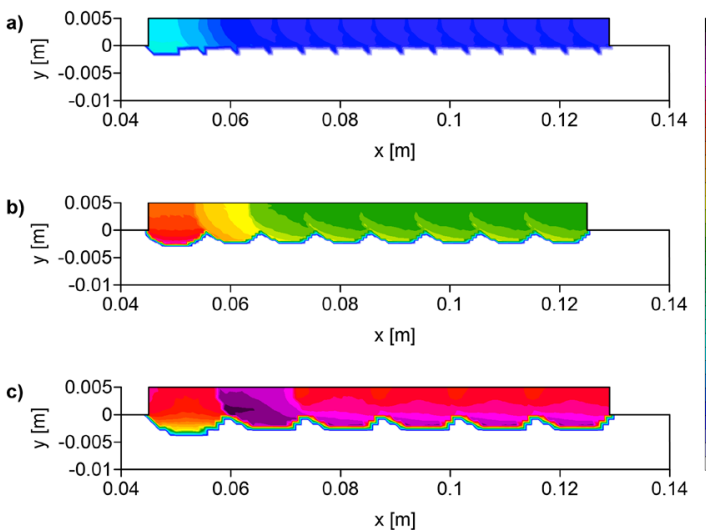

Fig. 17. Bainite fraction (after process), preheating temperature $473 \mathrm{~K}$ and padding weld width of: a) $0.006 \mathrm{~m}, \mathrm{~b}) 0.01 \mathrm{~m}, \mathrm{c}) 0.014 \mathrm{~m}$
The big differences in the distribution of the bainite structure, between the first and the other padding weld, were obtained. It was due to the
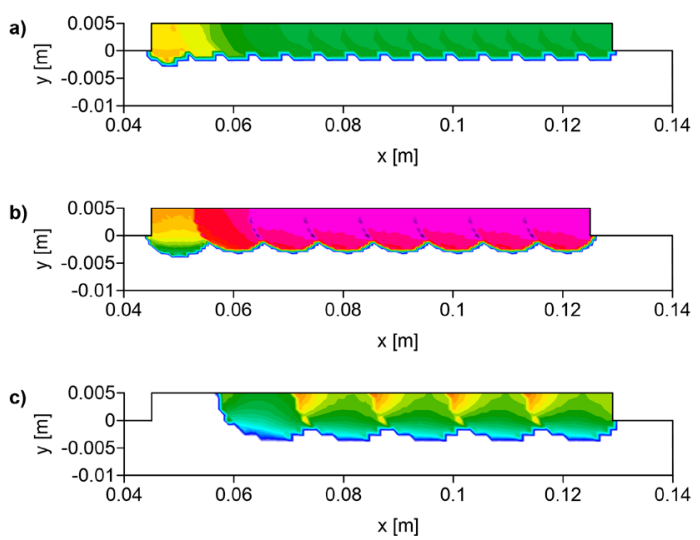

Fig. 18. Bainite fraction (after process), preheating temperature $573 \mathrm{~K}$ and padding weld width of:
a) $0.006 \mathrm{~m}, \mathrm{~b}) 0.01 \mathrm{~m}, \mathrm{c}) 0.014 \mathrm{~m}$
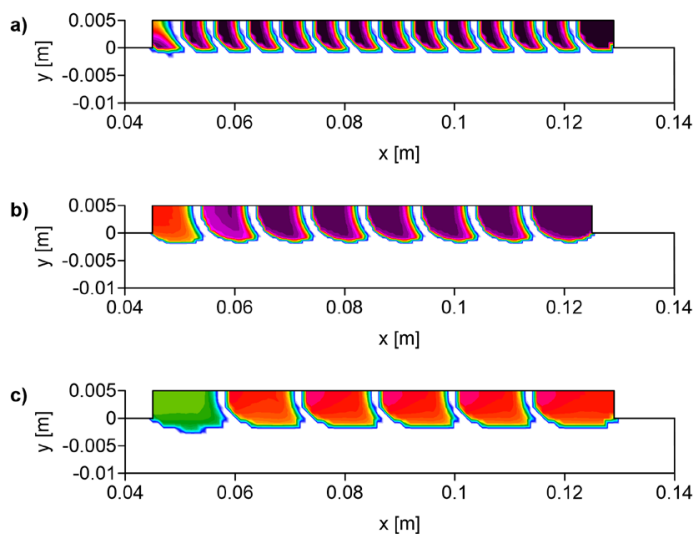

Fig. 19. Martensite fraction (after process), preheating temperature $293 \mathrm{~K}$ and padding weld width of:

a) $0.006 \mathrm{~m}, \mathrm{~b}) 0.01 \mathrm{~m}, \mathrm{c}) 0.014 \mathrm{~m}$
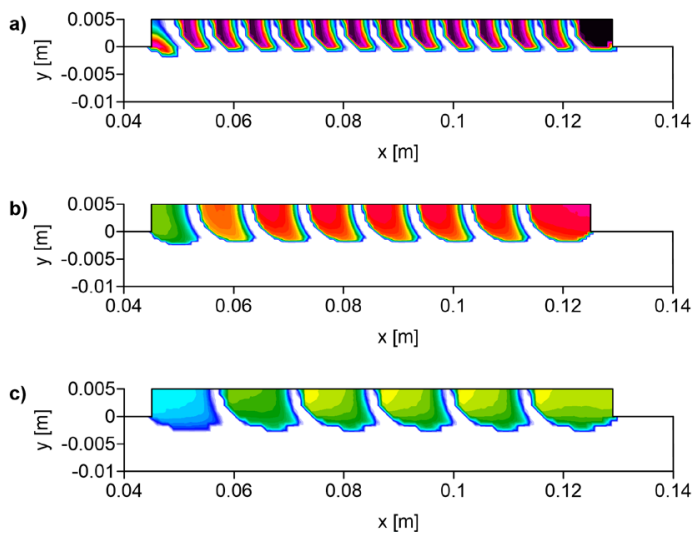

Fig. 20. Martensite fraction (after process), preheating temperature $373 \mathrm{~K}$ and padding weld width of: a) $0.006 \mathrm{~m}, \mathrm{~b}) 0.01 \mathrm{~m}, \mathrm{c}) 0.014 \mathrm{~m}$ 
different cooling conditions. The amount of bainite increases with the increase of the preheating temperature in the range $293 \mathrm{~K}$ to $473 \mathrm{~K}$ and the
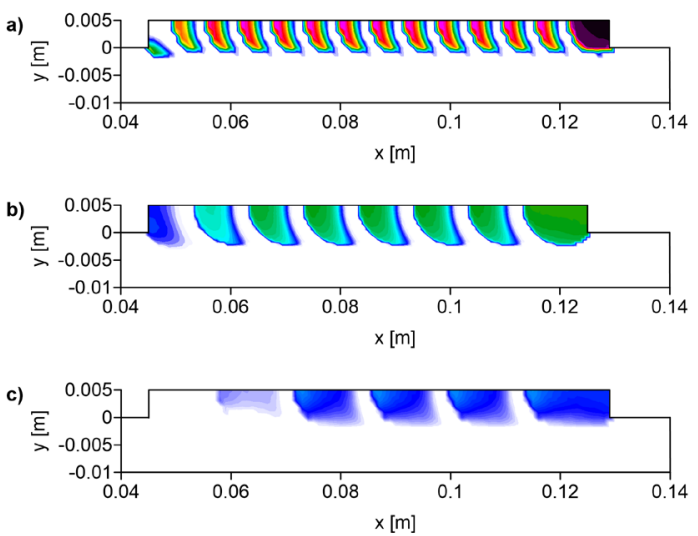

Fig. 21. Martensite fraction (after process), preheating temperature $473 \mathrm{~K}$ and padding weld width of: a) $0.006 \mathrm{~m}$, b) $0.01 \mathrm{~m}, \mathrm{c}) 0.014 \mathrm{~m}$
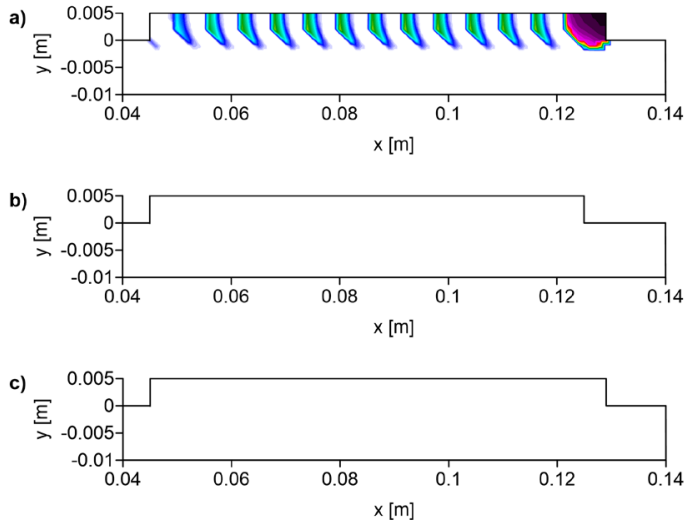

Fig. 22. Martensite fraction (after process), preheating temperature $573 \mathrm{~K}$ and padding weld width of: a) $0.006 \mathrm{~m}, \mathrm{~b}) 0.01 \mathrm{~m}, \mathrm{c}) 0.014 \mathrm{~m}$
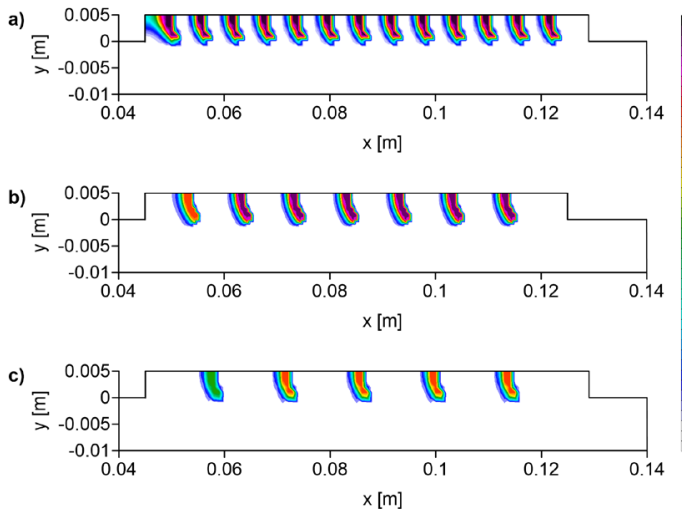

Fig. 23. Tempered martensite (after process), preheating temperature $293 \mathrm{~K}$ and padding weld width of: a) $0.006 \mathrm{~m}, \mathrm{~b}) 0.01 \mathrm{~m}, \mathrm{c}) 0.014 \mathrm{~m}$ padding weld width. The amount of bainite structure increases with the change of the PW width from 0.006 $\mathrm{m}$ to $0.01 \mathrm{~m}$. Whereas for the width of $0.014 \mathrm{~m}$ (Figs.
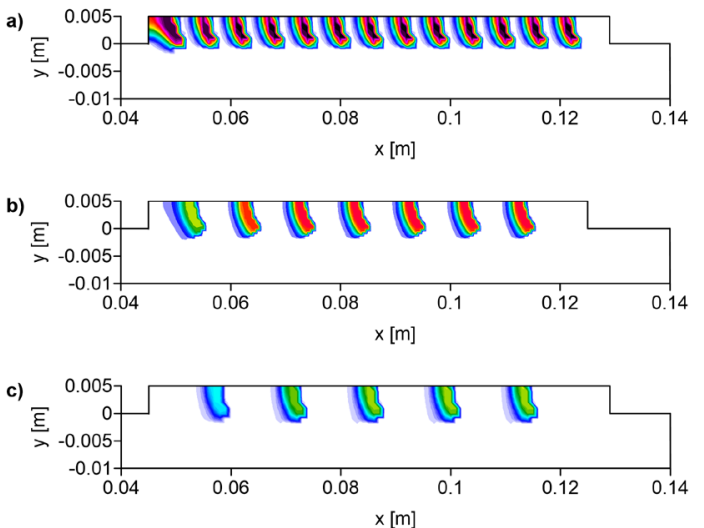

Fig. 24. Tempered martensite fraction (after process), preheating temperature $373 \mathrm{~K}$ and padding weld width of: a) $0.006 \mathrm{~m}, \mathrm{~b}) 0.01 \mathrm{~m}, \mathrm{c}) 0.014 \mathrm{~m}$
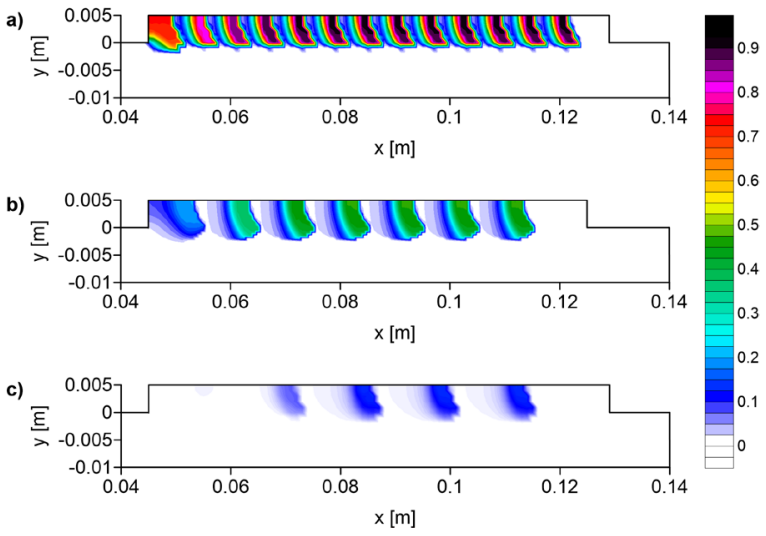

Fig. 25. Tempered martensite fraction (after process), preheating temperature $473 \mathrm{~K}$ and padding weld width of: a) $0.006 \mathrm{~m}, \mathrm{~b}) 0.01 \mathrm{~m}, \mathrm{c}) 0.014 \mathrm{~m}$
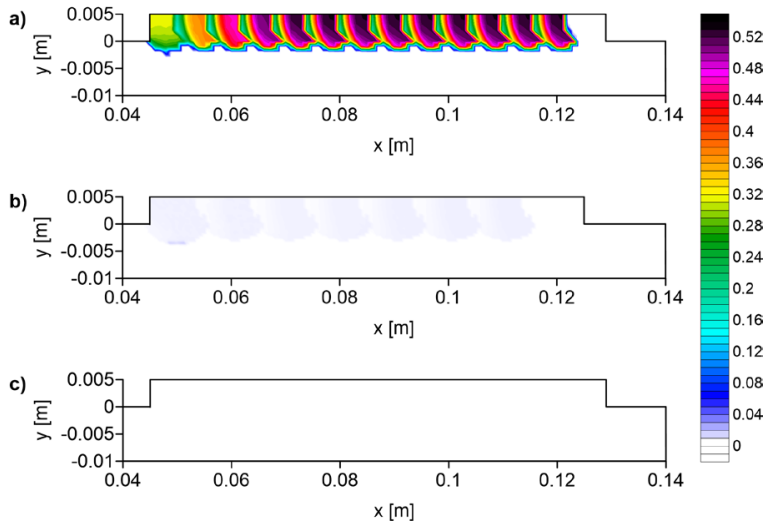

Fig. 26. Tempered martensite fraction (after process), preheating temperature $573 \mathrm{~K}$ and padding weld width of: a) $0.006 \mathrm{~m}, \mathrm{~b}) 0.01 \mathrm{~m}, \mathrm{c}) 0.014 \mathrm{~m}$ 
15 to 18) influence of the heat of the padding weld on the shape of the cooling curve on the CCT diagram, and thus a greater share of the ferrite-pearlite structure was noted (Figs. 11 to 14). The high repeatability of the distribution of phase composition in the central part of the material occurs for all cases.

The composition of the quenching phases (bainite, martensite, and tempered martensite; Table 2) indicates the rightness of using preheating in order to control the shape of cooling curves and the ferrite-pearlite structure (Figs. 19 to 26). The control of cooling curves, especially for hardly weldable materials, may cause a lower value of effective stress and in consequence elimination of cold cracks. As indicated by the results presented in Tables 2 and 3, the application of preheating at the level of $473 \mathrm{~K}$ and $573 \mathrm{~K}$ causes a much higher fraction of the bainite structure, which consequently reduces the yield point and the maximum values of effective stresses. This difference is especially visible for small volumes of the padding welds, where between the highest and the lowest preheating temperature, the difference in effective stresses reaches $64 \%$. It is less visible for wider padding welds, which, due to their volume, cool down more slowly (the difference between the bainite fraction for the smallest and the largest width of the padding weld without preheating temperature is over $40 \%$ ). The use of preheating only increases the fraction of bainite at the expense of martensite, until a ferrite-pearlite structure appears during cooling.

Table 2. The maximum values of the quenching structures

\begin{tabular}{cccc}
\hline $\begin{array}{c}\text { Analysis } \\
\text { No. }\end{array}$ & $\begin{array}{c}\text { Bainite } \\
{[\%]}\end{array}$ & $\begin{array}{c}\text { Martensite } \\
{[\%]}\end{array}$ & $\begin{array}{c}\text { Tempered } \\
\text { martensite [\%] }\end{array}$ \\
\hline 1.1 & 1.82 & 99.00 & 99.00 \\
\hline 1.2 & 9.49 & 97.89 & 97.87 \\
\hline 1.3 & 25.25 & 90.62 & 90.54 \\
\hline 1.4 & 59.25 & 53.58 & 53.26 \\
\hline 2.1 & 20.12 & 96.58 & 96.58 \\
\hline 2.2 & 37.07 & 82.80 & 82.83 \\
\hline 2.3 & 72.21 & 46.53 & 46.57 \\
\hline 2.4 & 85.52 & 0.42 & 1.13 \\
\hline 3.1 & 41.89 & 84.72 & 79.80 \\
\hline 3.2 & 61.17 & 60.42 & 56.16 \\
\hline 3.3 & 79.99 & 18.14 & 12.77 \\
\hline 3.4 & 63.60 & 0 & 0 \\
\hline
\end{tabular}

The distribution of plastic strains (Figs. 31 to 34) correctly indicates the areas where cracks can occur. Including recrystallization and loss of stress during heating significantly changes the results of calculations. The plastic strains were taken into account only below $70 \%$ of the solidus temperature of
C45 steel. The highest amount of tempered martensite occurred in the structure with a width of $0.006 \mathrm{~m}$ and a preheating temperature of $293 \mathrm{~K}$ (Fig. 23a).

Table 3. Summary of the calculation results for the considered cases after the regeneration process

\begin{tabular}{cccr}
\hline $\begin{array}{c}\text { Analysis } \\
\text { No. }\end{array}$ & $\begin{array}{c}\text { Maximum } \\
\text { effective } \\
\text { stresses [MPa] }\end{array}$ & $\begin{array}{c}\text { Maximum } \\
\text { effective } \\
\text { plastic strain }\end{array}$ & $\begin{array}{c}\text { Yield point } \\
\text { [MPa] }\end{array}$ \\
\hline 1.1 & 947.00 & 0.0066 & $314.12-1217.05$ \\
\hline 1.2 & 862.90 & 0.0057 & $312.68-1202.54$ \\
\hline 1.3 & 876.54 & 0.0044 & $312.12-1132.65$ \\
\hline 1.4 & 577.56 & 0.0044 & $311.87-844.20$ \\
\hline 2.1 & 827.53 & 0.0070 & $313.42-1210.20$ \\
\hline 2.2 & 605.72 & 0.0055 & $312.51-1088.32$ \\
\hline 2.3 & 659.55 & 0.0054 & $312.07-804.80$ \\
\hline 2.4 & 466.05 & 0.0057 & $294.01-472.88$ \\
\hline 3.1 & 451.99 & 0.0051 & $313.11-1089.22$ \\
\hline 3.2 & 421.45 & 0.0040 & $312.38-886.11$ \\
\hline 3.3 & 416.08 & 0.0034 & $312.00-582.29$ \\
\hline 3.4 & 403.88 & 0.0033 & $310.48-434.41$ \\
\hline
\end{tabular}

The stress distributions for the first three preheating temperatures, with the assumed cooling conditions, were similar to the maximum values (Figs. 27 to 29). The influence of the padding weld width on the stress level was observed. The differences between the maximum values of effective stresses for the case without preheating even reach $100 \%$ (analysis No. 3.1 and 1.1). This difference decreases for the analysis No. 3. to less than $5 \%$ (Table 3). The most favourable was the distribution for a $0.014 \mathrm{~m}$ of padding width. The effective stress value for temperature $573 \mathrm{~K}$ was caused by the yield point value for analysed material (Table 3). The yield point value was due to the high proportion of the ferrite-pearlite structure in relation to martensite. Reduction in the level of effective stresses with an increased number of padding welds was observed. Along with the increase of the padding weld width, the stresses were initialized deeper in the base material (Figs. 27 to 30).

The distribution and kinetics of phase transformations in the solid state determines the distribution of the yield point. Higher values of yield point occurred for areas with the highest cooling rate and martensite transformation (Table 3). The assumed yield point of tempered martensite, at the level of bainite, were caused by the reduction of the yield point in the interpass areas. The temperaturedependent yield point values for the individual phases are shown in Fig. 4.

The level of plastic strains decreased when the preheating temperature and padding weld width were 
increased. The greatest plastic strains occurred for the smallest width of the padding weld. The plastic strains increase towards the padding weld surface. They decrease with the width of the padding weld
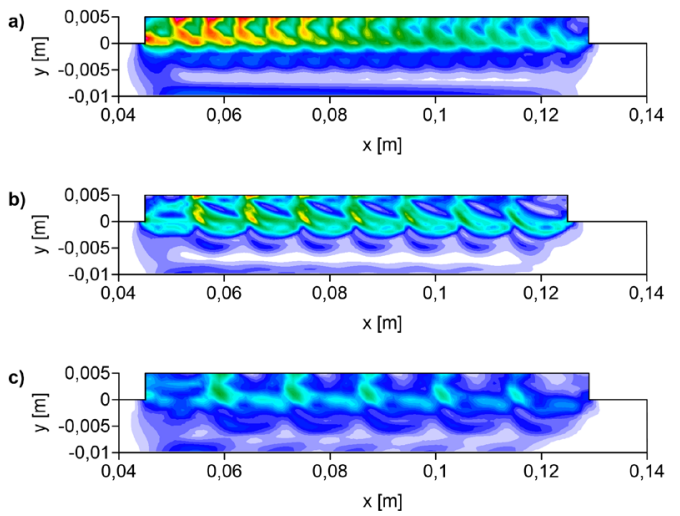

Fig. 27. Effective stresses [MPa] (after process), preheating temperature $293 \mathrm{~K}$ and padding weld width of: a ) $0.006 \mathrm{~m}, \mathrm{~b}) 0.01 \mathrm{~m}, \mathrm{c}) 0.014 \mathrm{~m}$
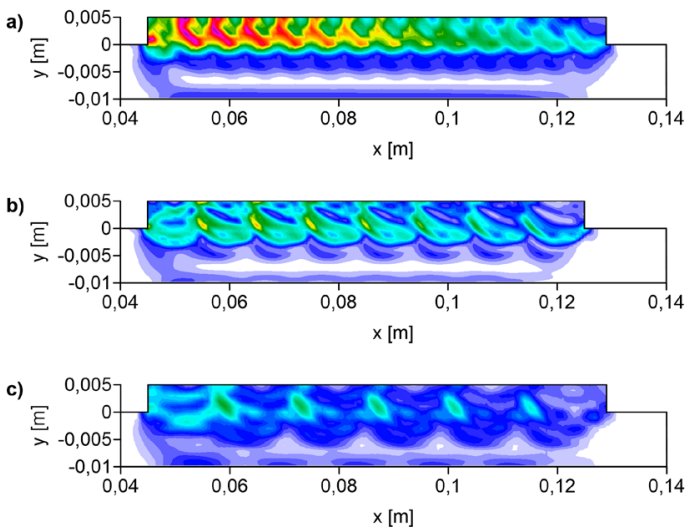

Fig. 28. Effective stresses [MPa] (after process), preheating temperature $373 \mathrm{~K}$ and padding weld width of: a) $0.006 \mathrm{~m}$, b) $0.01 \mathrm{~m}, \mathrm{c)} 0.014 \mathrm{~m}$
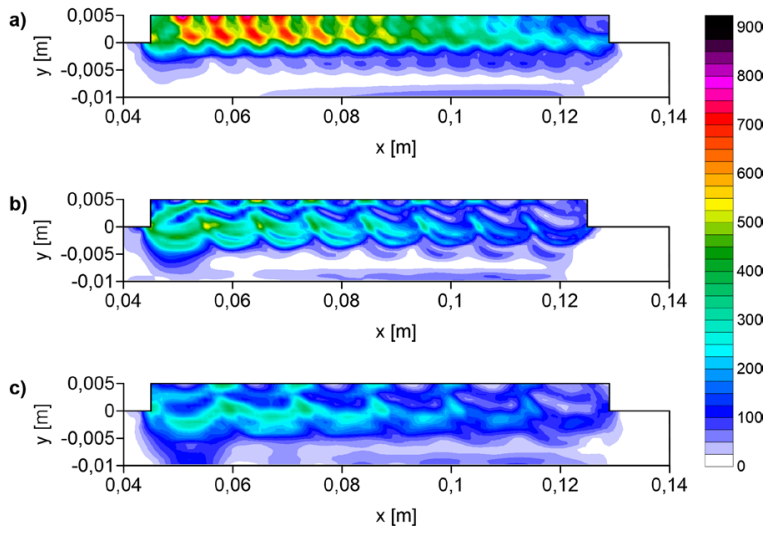

Fig. 29. Effective stresses [MPa] (after process), preheating temperature $473 \mathrm{~K}$ and padding weld width of: a) $0.006 \mathrm{~m}$, b) $0.01 \mathrm{~m}, \mathrm{c)} 0.014 \mathrm{~m}$
(Table 3). The distribution of plastic strains suggests the formation of cracks between welds, especially for smaller widths of the padding weld and a lower preheating temperature. The influence of the
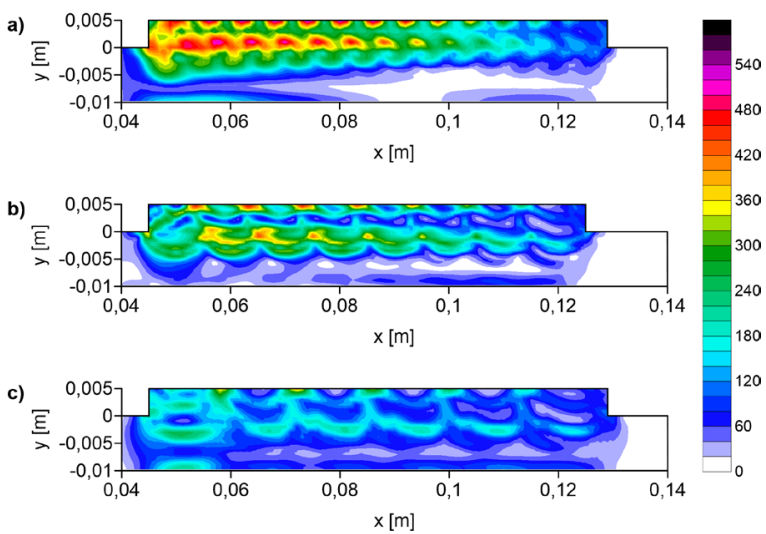

Fig. 30. Effective stresses [MPa] (after process), preheating temperature $573 \mathrm{~K}$ and padding weld width of: a) $0.006 \mathrm{~m}, \mathrm{~b}) 0.01 \mathrm{~m}, \mathrm{c}) 0.014 \mathrm{~m}$

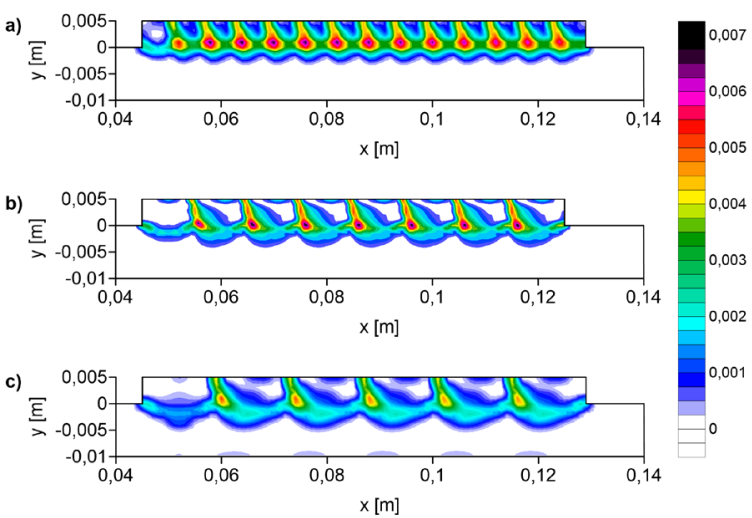

Fig. 31. Effective plastic strain (after process), preheating temperature $293 \mathrm{~K}$ and padding weld width of: a) $0.006 \mathrm{~m}, \mathrm{~b}) 0.01 \mathrm{~m}, \mathrm{c}) 0.014 \mathrm{~m}$
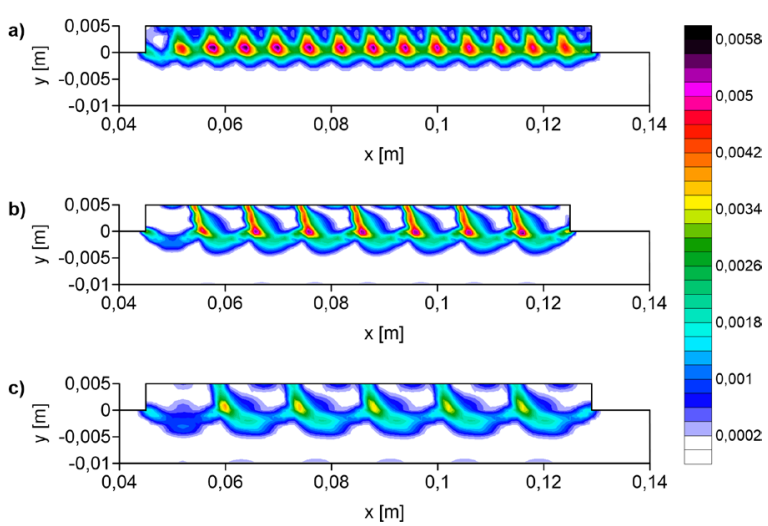

Fig. 32. Effective plastic strain (after process), preheating temperature $373 \mathrm{~K}$ and padding weld width of: a) $0.006 \mathrm{~m}, \mathrm{~b}) 0.01 \mathrm{~m}, \mathrm{c}) 0.014 \mathrm{~m}$ 
martensite tempering and recrystallization process was observed (Figs. 31 to 34 ).

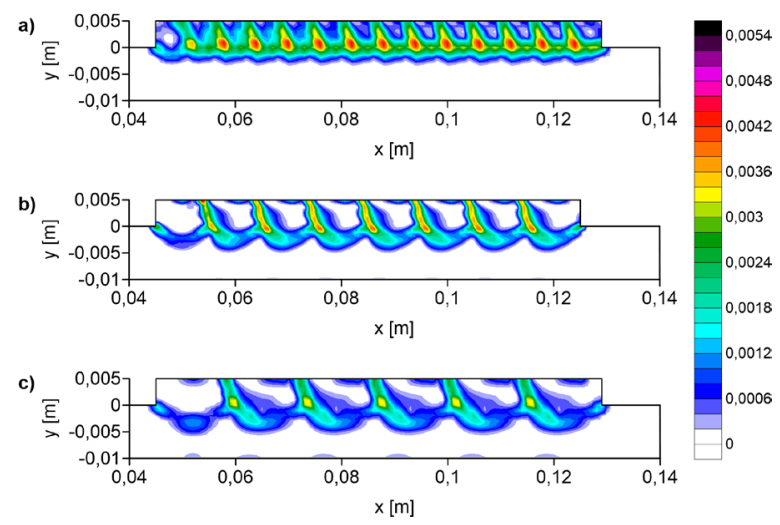

Fig. 33. Effective plastic strain (after process), preheating temperature $473 \mathrm{~K}$ and padding weld width of: a) $0.006 \mathrm{~m}$, b) $0.01 \mathrm{~m}, \mathrm{c}) 0.014 \mathrm{~m}$

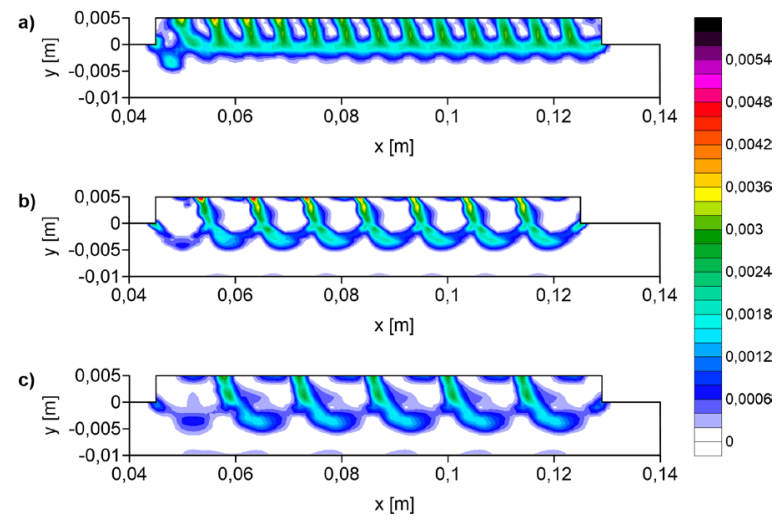

Fig. 34. Effective plastic strain (after process), preheating temperature $573 \mathrm{~K}$ and padding weld width of: a) $0.006 \mathrm{~m}, \mathrm{~b}) 0.01 \mathrm{~m}, \mathrm{c)} 0.014 \mathrm{~m}$

\section{CONCLUSIONS}

In the present paper, the influence of padding weld width and preheating temperature on phase transformations and stresses of the regenerated layer were analysed. The obtained results indicate that the use of preheating in order to change the shape of cooling curve, even until complete cooling, makes it possible to control the fraction of individual phases. However, the economic analysis of this process indicates that it would be more convenient, cheaper and more effective to control cooling conditions than heating. The obtained results give answers to questions about structures in the regeneration process, during which we did not have full control over the process conditions (the process was not controlled by the interpass temperature). This is applicable if the cooling process has not been stopped when the interpass temperature is reached at the level of preheating temperature only at the level of the ambient temperature. An example of such a process may be the performance of the next long padding welds with a long technological break, where the beginning of the padding weld is cooled to ambient temperature before the next pad.

On the basis of the presented results and taking into account the stress distribution, it can be concluded that the use of the widest padding weld is highly advantageous. The use of preheating for analysis No. 3 is not required to obtain a hard but also brittle surface (high fraction of martensite). The selection of the optimal preheating value is possible only when we define the conditions under which the pad welding surface will work. If we want to obtain a large amount of bainite structure and small amount of martensite, the lowest suggested preheating is between $373 \mathrm{~K}$ and $473 \mathrm{~K}$. Obtaining areas of tempered martensite is beneficial for regenerated surfaces. However, due to the specificity of pad welding, the area of tempered martensite cannot, especially for small padding welds, reach too deep into the pad welding without additional treatment. Therefore, during pad welding, we should focus on obtaining a bainite structure with the addition of martensite, whereas the area of tempered martensite treat as an additional advantage. However, it should be noted that in choosing large cross-sectional padding welds, problems may occur with the segregation of the admixture, the influence of the temperature of the padding weld on the base material or the noticeable higher values of plastic strains and the stresses inside the regenerated material.

The results obtained from the analysis of the phase transformations in the solid state and stresses suggest that it is unreasonable to use heating and cooling sequentially to ambient temperature; this is also not economically viable. Therefore, it is reasonable to consider the case in which the next padding weld is applied when the temperature of the previous padding has reached the preheating temperature. The differences between the obtained distributions of plastic strains result from the influence of the preheating temperature, before each padding weld, on the cooling rate.

As previously mentioned, the analysed material is very difficult to regenerate. The presented analysis allows one to assess whether there may be defects after the regeneration process in the absence of appropriate supervision. With unfavourable distribution of structural and thermal strains, cracks may occur in the cross-section of the PW (this would require a 3D analysis). 
In this paper, a geometrically simple case that can be easily referred to in experimental research or other computer simulation models was considered. However, in practical applications, where the shape of the pad welding object may be very different, the presented results cannot be transferred.

\section{ACKNOWLEDGEMENTS}

The research has been performed within a statutory research BS/PB-1-100-3010/2020/P.

\section{REFERENCES}

[1] Odebiyi, O.S., Adedayo, S.M., Tunji, L.A., Onuorah, M.O. (2019). A review of weldability of carbon steel in arc-based welding processes. Cogent Engineering, vol. 6, no. 1, p. 1609180, Dol:10.1080/23311916.2019.1609180.

[2] Nowacki, J., Wypych, A. (2010). Application of thermovision method to welding thermal cycle analysis. Journal of Achievements in Materials and Manufacturing Engineering, vol. 40, no. 2, p. 131-137.

[3] Hu, Z., Qin, X., Shao, T. (2017). Welding thermal simulation and metallurgical characteristics analysis in WAAM for 5 CrNiMo hot forging die remanufacturing. Procedia Engineering, vol. 207, p. 2203-2208, DOl:10.1016/j.proeng.2017.10.982.

[4] Zhou, X., Liu, Y., Liu, C., Yu, L., Li, H. (2018). Austenitizing temperature effects on the martensitic transformation, microstructural characteristics, and mechanical performance of modified ferritic heat-resistant steel. Metallurgical and Materials Transactions A, vol. 49, p. 3525-3538, Dol:10.1007/ s11661-018-4723-z.

[5] Chen, X.Z., Huang, Y.M., Shen, Z., Chen, J., Lei, Y.C., Zhou, J.Z. (2013). Effect of thermal cycle on microstructure and mechanical properties of CLAM steel weld CGHAZ. Science and Technology of Welding and Joining, vol. 18, no. 4, p. 272278, DOI:10.1179/1362171812Y.0000000095.

[6] Marques, M.J., Ramasamy, A., Batista, A.C., Nobre, J.P., Loureiro, A. (2015). Effect of heat treatment on microstructure and residual stress fields of a weld multilayer austenitic steel clad. Journal of Materials Processing Technology, vol. 222, p. 52-60, DOI:10.1016/j.jmatprotec.2015.03.004.

[7] Jiang, W.C., Wang, B.Y., Gong, J.M., Tu, S.T. (2011). Finite element analysis of the effect of welding heat input and layer number on residual stress in repair welds for a stainless steel clad plate. Materials \& Design, vol. 32, no. 5, p. 2851-2857, D0l:10.1016/j.matdes.2010.12.037.

[8] Liu, S., Sun, J., Wei, F., Lu, M. (2018). Numerical simulation and experimental research on temperature and stress fields in TIG welding for plate of RAFM steel. Fusion Engineering and Design, vol. 136, part A, p. 690-693, D0l:10.1016/j. fusengdes.2018.03.058.

[9] Jeffus, L. (2020) Welding: Principles And Applications (9th ed.). Cengage Learning, Boston.

[10] Kuzniecow, V.D., Popowicz, P.W. (2011). Problems of restoration medium and high-carbon steels by hard- facing. Welding Technology Review, vol. 83, no. 10, p. 4-7, D0I:10.26628/wtr.v83i10.460. (in Polish)

[11] ISO 5817 (2014). Welding - Fusion-Welded Joints in Steel, Nickel, Titanium and Their Alloys (Beam Welding Excluded) Quality Levels for Imperfections. International Organization for Standardization, Geneva.

[12] Pfeifer, T., Czwórnóg, B. (2015). The effect of plasma surfacing parameters on the geometry and structure of overlay welds. Institute of Welding Bulletin, vol. 59, no. 4, p. 6-14, DOI:10.17729/ebis.2015.4/1.

[13] Winczek, J. (2017). Modeling of temperature field during multipass GMAW surfacing or rebuilding of steel elements taking into account the heat of the deposit metal. Applied Sciences, vol. 7, no. 1, p. 6, DOl:10.3390/app7010006.

[14] Bęczkowski, R., Wróbel, J., Kulawik, A. (2017). The use of numerical modelling to determine the conditions of regeneration of medium carbon steel. Archives of Metallurgy and Materials, vol. 62, no. 4, p. 2223-2230, Dol:10.1515/ amm-2017-0328.

[15] Wróbel, J., Kulawik, A. (2018). Analysis of the influence of material parameters of the numerical model on the obtained shape of the heat affected zone for the TIG heating process. AIP Conference Proceedings, vol. 1978, p. 470029, DOl:10.1063/1.5044099.

[16] Bokota, A. (2012). Modelling of Hardening Tool Steels: Thermal Phenomena, Phase Transformations, Mechanical Phenomena. Wydawnictwo Politechniki Częstochowskiej, Czestochowa. (in Polish)

[17] Piekarska, W., Kubiak, M., Bokota, A. (2011). Numerical simulation of thermal phenomena and phase transformations in laser-arc hybrid welded joints. Archives of Metallurgy and Materials, vol. 56, no. 2, p. 409-421, D0l:10.2478/v10172011-0044-6.

[18] Wever, F., Rose, A. (1961). Atlas zur Wärmebehandlung von Stähle, I Zeit Temperatur Umwandlungs Schaubilder, Verlag Stahleisen, Düsseldorf.

[19] Bokota, A., Kulawik, A. (2007). Model and numerical analysis of hardening process phenomena for medium-carbon steel. Archives of Metallurgy and Materials, vol. 52, no. 2, p. 337346.

[20] Koistinen, D.P., Marburger, R.E. (1959). A general equation prescribing the extent of the austenite-martensite transformation in pure iron-carbon alloys and plain carbon steels. Acta Metallurgica, vol. 7, no. 1, p. 59-60, DOI:10.1016/0001-6160(59)90170-1.

[21] Avrami, M. (1939). Kinetics of phase change. I General theory. Journal of Chemical Physics, vol. 7, no. 12, p. 1103-1112, DOl:10.1063/1.1750380.

[22] Winczek, J., Kulawik, A. (2015). Dilatometric and hardness analysis of C45 steel tempering with different heating-up rates. Metalurgija, vol. 51, no. 1, p. 9-12.

[23] Fischer, F.D., Reisner, G., Werner, E., Tanaka, K., Cailletaud, G., Antretter, T. (2000). A new view on transformation induced plasticity (TRIP). International Journal of Plasticity, vol. 16, no. 7-8, p. 723-748, Dol:10.1016/S0749-6419(99)00078-9.

[24] Taleb, L., Cavallo, N., Waeckel, F. (2001). Experimental analysis of transformation plasticity. International Journal of Plasticity, vol. 17, no. 1, p. 1-20, Dol:10.1016/S0749-6419(99)00090-X. 
[25] Coret, M., Combescure, A. (2002). A mesomodel for numerical simulation of the multiphasic behavior of materials under anisothermal loading (application to two low-carbon steels). International Journal of Mechanical Sciences, vol. 44, no. 9, p. 1947-1963, D0I:10.1016/S0020-7403(02)00053-X.

[26] Intel® (2020). Math Kernel Library, from https://software. intel.com/en-us/mkl, accessed on 28.02.2020.
[27] Zienkiewicz, O.C., Taylor, R.L. (2000). The Finite Element Method, Butterworth-Heinemann, Oxford.

[28] Li, C., Wang, Y., Zhan, H., Han, T., Han, B., Zhao, W. (2010). Three-dimensional finite element analysis of temperatures and stresses in wide-band laser surface melting processing. Materials \& Design, vol. 31, no. 7, p. 3366-3373, D0l:10.1016/j.matdes.2010.01.054. 